\title{
Temporal changes in medical student perceptions of their clinical skills and needs using a repeated self-assessment instrument
}

Patrick Barlow ${ }^{1}$, Robert Humble ${ }^{2}$ and Amal Shibli-Rahhal ${ }^{1 *}$

\begin{abstract}
Background: Medical student needs in clinical skill training may change over time, but data on this topic are limited. This study uses repeated self-assessments on clinical rotations during medical school to evaluate students' perceptions of their clinical skill growth.

Methods: A self-assessment rating was completed by students during each clinical rotation as they progressed through their core clinical rotation year. The instrument consisted of questions on 5 clinical skill categories where students rated their performance as "below", "at" or "above" expected, and open-ended questions on strengths and challenges. We evaluated changes in self-ratings between the first $(n=136)$ and third $(n=118)$ quarters by matchedpair analysis of the shift in responses between time points using a Sign Test. We also identified the main themes from the students' responses to open-ended questions.
\end{abstract}

Results: We found $22.4 \%$ and $13.3 \%$ of students increased their self-assessment ratings on "Oral Presentation Skills" and on "Differential Diagnosis", respectively. In contrast, perceived ability to communicate with patients saw the largest negative shifts. "Patient Interaction" was the most commonly identified area of strength and "Knowledge and Organization" was most frequently cited as a barrier.

Conclusions: Students demonstrated a positive shift in perceived competence in some core clinical skills that are not strongly emphasized in the preclinical curriculum, likely reflecting increased exposure over time. However, their perceived competence in communication skills declined. This may reflect initial over-estimation or true decline due to competing needs/interests. These patterns of change can inform the design of longitudinal curricula that anticipate and address students' needs during clinical rotations, such as placing increased emphasis on presentation skills and differential diagnosis earlier in the curriculum, and adding more emphasis to communication skills in later phases.

Keywords: Clinical clerkship, Self-assessment, Clinical training, Clinical curriculum

\section{Background}

Learner self-assessment is an important component of the formative evaluation necessary to the development of a student's lifelong learning skills [1]. Lifelong learning is particularly important in the medical profession given

\footnotetext{
*Correspondence: Amal-rahhal@uiowa.edu

1 Department of Internal Medicine, University of lowa Carver College of Medicine, 1216H MERF, 375 Newton Rd, IA 52242-2600 lowa City, USA Full list of author information is available at the end of the article
}

that physicians have a professional obligation to maintain adequate knowledge and skills, which often relies on their willingness and ability to engage with self-directed learning [2]. This, combined with the rapid changes and advances in the field of medicine and health sciences, makes the ability to engage in self-directed learning a necessary skill. While opinions on the accuracy of individual self-assessments are mixed [3], the general ability to self-assess is widely considered an important learning 
tool for developing physicians [4]. In fact, self-assessment is associated with enhanced learner motivation and selfregulated learning [5-10]. Self-efficacy, a different but related concept that refers to an individual's confidence in their ability to demonstrate a certain performance [11], has also been shown to play an integral role in learners' motivation and engagement with the learning process [12-15]. Consequently, an argument could be made for medical schools and educators to adapt some of their longitudinal curricula to the evolving self-perceived needs of students, in order to promote optimal engagement and learning. However, studies on the topic of self-assessment in clinical education tend to be specialty-specific and limited to within individual clinical rotations. Additionally, most studies on self-assessment have collected student data at a single timepoint without follow-up [16], so how self-assessment changes as students' progress through their clinical rotations has not been evaluated.

The present study aims to explore the potential to measure student perceived clinical growth over the course of their core clinical rotations, regardless of rotation specialty, using self-assessment ratings on a standard mid-rotation assessment instrument.

\section{Methods}

\section{Setting}

The University of Iowa Carver College of Medicine admits roughly 145 students to its Doctor of Medicine program each year. The curriculum consists of three main phases. Phase I is 18 months long and consists of the preclinical curriculum. This is followed by Phase II where students spend twelve months, divided into four 12-week blocks, rotating on nine core clinical rotations: (1) Inpatient Internal Medicine (IM), (2) Pediatrics, (3) General Surgery, (4) Obstetrics \& Gynecology (OB/ GYN), (5) Psychiatry, (6) Neurology, (7) Outpatient Internal Medicine (OIM), (8) Family Medicine, and (9) Community-Based Primary Care (CBPC). During Phase II, students also participate in 2 short non-core rotations of their choosing. Finally, students move into the 18-months long phase III where they participate in advanced (subinternship, intensive care, emergency medicine) and elective clinical rotations and courses.

\section{Instrument development}

The mid-rotation assessment instrument was created in close consultation with core clinical rotation directors, medical students, curriculum leadership, and faculty with program evaluation and assessment expertise. We started by conducting a survey of the stakeholders to assess the most crucial elements that should be addressed in the mid-rotation assessment, and those responses were discussed during several meetings with the different stakeholders until consensus was achieved. The instrument was ultimately designed to gather three pieces of information. The first part of the instrument is a student self-assessment of their perceived performance in five categories, with several items under each category: (1) Knowledge/Clinical Reasoning (3 items), (2) Clinical Evaluation Skills (3 items), (3) Data Presentation Skills (2 items), (4) Studying Skills (3 items), and (5) Team Work (3 items). Students provide an ordinal rating (1 "Below expected level", 2 "At expected level", 3 "Above expected level") of their perceived abilities across these areas as well as written comments on their perceived strengths, weaknesses, and plans for improving. We did not provide a definition of "expected level" to the students as we were interested in capturing their perception of their performance as they self-define it. The second part of the instrument evaluates the student's progress towards meeting the rotation requirements such as their required clinical experiences. The third part is a narrative (i.e., written) feedback provided by the clinical preceptor or rotation director on strengths and strategies for improvement and continued development that is informed by the student self-assessment. While not the only source for feedback, the self- assessment component of the instrument aims to guide this narrative feedback and make it learner-centered. The specific questions on the instrument were piloted with a small group of students and faculty evaluators. After 3 months of use, the student-self-assessments and narrative clinical preceptor feedback were analyzed and shared with the stakeholders. Additional training to evaluators was provided based on these analyses.

\section{Data collection}

The mid-rotation feedback process constitutes a required element for medical school accreditation in the United States. Consequently, during each of the nine core clinical rotations of Phase II, the students participate in a mandatory mid-rotation feedback session with their primary clinical preceptor or rotation director. Students complete the self-assessment portion of the instrument shortly before these meetings and submit the form electronically to a central tracking application. Thus, each student completes a total of nine self-assessments over the course of 12 months. The present study focuses on the student self-assessment portions of the mid-rotation feedback instrument (Additional file 1) using data stored in the central tracking application. The self-assessment forms were de-identified by a curriculum manager and each student was assigned a random number that was placed on their forms to allow data matching. The researchers involved in this study had no access to student information. This study was reviewed by the University of Iowa 
Institutional Review Board (IRB) and was determined not to meet the federal regulatory definition of human subjects research.

\section{Data analysis}

We compared student self-assessments performed during the first 12-week block of Phase II to those performed during the third block. We pursued an embedded mixedmethods design in which the analysis of the self-assessment data, which included a quantitative analysis of the matched and unmatched ratings, were then bolstered by a comparative qualitative content analysis of open-ended comments [17].

\section{Self-assessment ratings}

Self-assessment ratings were analyzed with a combination of descriptive statistics including frequencies and percentages. The percent change from the first to third 12-week block (Block 1 and Block 3 respectively) was assessed for the whole sample by category and by individual items within each category. A matched-pair analysis of the shift in responses between time points was analyzed using a Sign Test, which evaluates each matched pair of ratings for negative differences, positive differences, and ties. An example of each in the context of our study is found in the table below. These matched pairs were defined as a single student's Block 1 and Block 3 scores, and all students for whom we could not match a Block 1 and Block 3 score were excluded from that particular analysis. As there are no readily available measures of effect size for many non-parametric tests including the Sign Test, we used the procedures described by Rosenthal and Rubin [18] to calculate a $r_{\text {equivalent }}$ value for any statistically significant result. They described their procedure was acceptable in cases where, "...(a) the alternative is to have no effect size estimate at all (e.g., only sample sizes and p values are known for a study), [and] (b) nonparametric procedures were used for which there are no currently accepted effect size indicators (p. 496)". The values are interpreted as a pointbiserial correlation between each pair of variables where values of $|0.1|,|0.3|$, and $|0.5|$ would be considered small, medium, and large effects, respectively, using the conventions laid out by Cohen [19]. Statistical tests were 2-sided and $p<0.05$ was considered statistically significant. Analysis was completed using SPSS v25 (IBM, Inc.).

\begin{tabular}{lll}
\hline Negative Difference & 3 "Above expected level" & 2 "At expected level" \\
Positive Difference & 1 "Below expected level" & 2 "At expected level" \\
Tie & 2 "At expected level" & 2 "At expected level" \\
Sign Test Outcome & First Rating & Second Rating \\
\hline
\end{tabular}

\section{Open-ended comments}

Qualitative content analysis is a flexible method for analyzing text data that varies in approach depending on the specific problem being studied [20]. Conventional content analysis involves deriving salient themes/codes directly from the text while directed content analysis relies on previous data and theory to develop themes/ codes a priori and apply them to the text [20]. We use both approaches in this study. Conventional content analysis was used with Block 1 data because we did not make assumptions about the types of strengths and barriers that the students would share. We then used the codes developed from the first set of data and applied them to a directed content analysis of Block 3 data, so that direct comparisons could be made between the two time points.

All data were entered into Microsoft Excel for analysis. Then, both sets of data were analyzed independently by two raters (RH, PB). Disagreements were resolved to obtain a final consensus coding. The frequencies of each code were compared across the two time points to observe the progression of students' perceived skills as they gained more experience in their core clinical year. The prevalence of each code was also compared across each of the different rotations. Results are summarized using frequencies and percentages as well as representative comments unique to each theme.

\section{Results}

Since completion of the mid-rotation assessment instrument was a required part of each rotation, our samples for Block $1(n=136)$ and Block $3(n=118)$ reflect $100 \%$ of the students taking the applicable rotations during the time the forms were collected. The discrepancy between the numbers of students in Block 1 and 3 is due to some students being on a leave of absence from their studies and to others participating in short non-core rotations during Phase II of the curriculum where mid-rotation feedback is not required. Of these 254 total forms, 100 were successfully matched between a student's Block 1 and Block 3 self-assessment ratings. Unmatched students were those who did not participate in any clinical rotations or were scheduled to take a non-core rotation that did not require the self-assessment instrument to be completed during one of the collection periods. Table 1 shows the breakdown of each sample by rotation.

\section{Self-assessment ratings}

Figure 1 displays the changes in frequency for each of the self-assessment ratings in the unmatched (i.e., full) sample. Within each item, we observed an increase in the proportion of students rating themselves "At 
Table 1 Proportion of Students in Each Clinical Rotation by Sample

\begin{tabular}{|c|c|c|c|}
\hline \multirow[t]{2}{*}{ Rotation } & \multicolumn{3}{|c|}{ Frequency (\%) by Sample } \\
\hline & Block $1(n=136)$ & Block $3(n=118)$ & Total $(N=254)$ \\
\hline Community-Based Primary Care (CBPC) & $12(8.8 \%)$ & $10(8.5 \%)$ & $22(8.7 \%)$ \\
\hline Family Medicine & $11(8.1 \%)$ & $14(11.9 \%)$ & $25(9.8 \%)$ \\
\hline Inpatient Internal Medicine (IM) & $18(13.2 \%)$ & $15(12.7 \%)$ & $33(13.0 \%)$ \\
\hline Neurology & $15(11.0 \%)$ & $9(7.6 \%)$ & $24(9.4 \%)$ \\
\hline Obstetrics \& Gynecology (OB/GYN) & $19(14.0 \%)$ & $16(13.6 \%)$ & $35(13.8 \%)$ \\
\hline Outpatient Internal Medicine (OIM) & $11(8.1 \%)$ & $13(11.0 \%)$ & $24(9.4 \%)$ \\
\hline Pediatrics & $21(15.4 \%)$ & $17(14.4 \%)$ & $38(15.0 \%)$ \\
\hline Psychiatry & $15(11.0 \%)$ & $9(7.6 \%)$ & $24(9.4 \%)$ \\
\hline Surgery & $20(14.7 \%)$ & $15(12.7 \%)$ & $35(13.8 \%)$ \\
\hline
\end{tabular}

expected level" from Block 1 to Block 3. This was paralleled with a decrease in the proportion of students rating themselves "Below expected level" on several items, specifically "Differential Diagnosis", "Oral Presentations", and "Balancing Clinical Work and Studying". On the other hand, we also saw a decreased in the proportion of students rating themselves "Above expected level" for every item except "Physical Exam Skills" and "Oral Presentations".

The matched comparisons of 100 students' Block 1 and Block 3 ratings yielded results that largely supported the percent-change results from the unmatched sample (Fig. 2). We found a statistically significant number of positive shifts in self-assessment ratings on "Oral Presentation Skills" from Block 1 to Block 3, with $22.4 \%$ of students increasing their rating by at least one level $\left(r_{\text {equivalent }}\right.$ $=0.36, p<0.001$ ). We also saw a significant positive shift in self-assessment ratings on "Differential Diagnosis", with $13.3 \%$ of students increasing their rating on this skill $\left(r_{\text {equivalent }}=0.17, p=0.049\right)$. In contrast, students' perceived ability to communicate with patients saw the largest proportion of negative shifts from Block 1 to Block 3 .

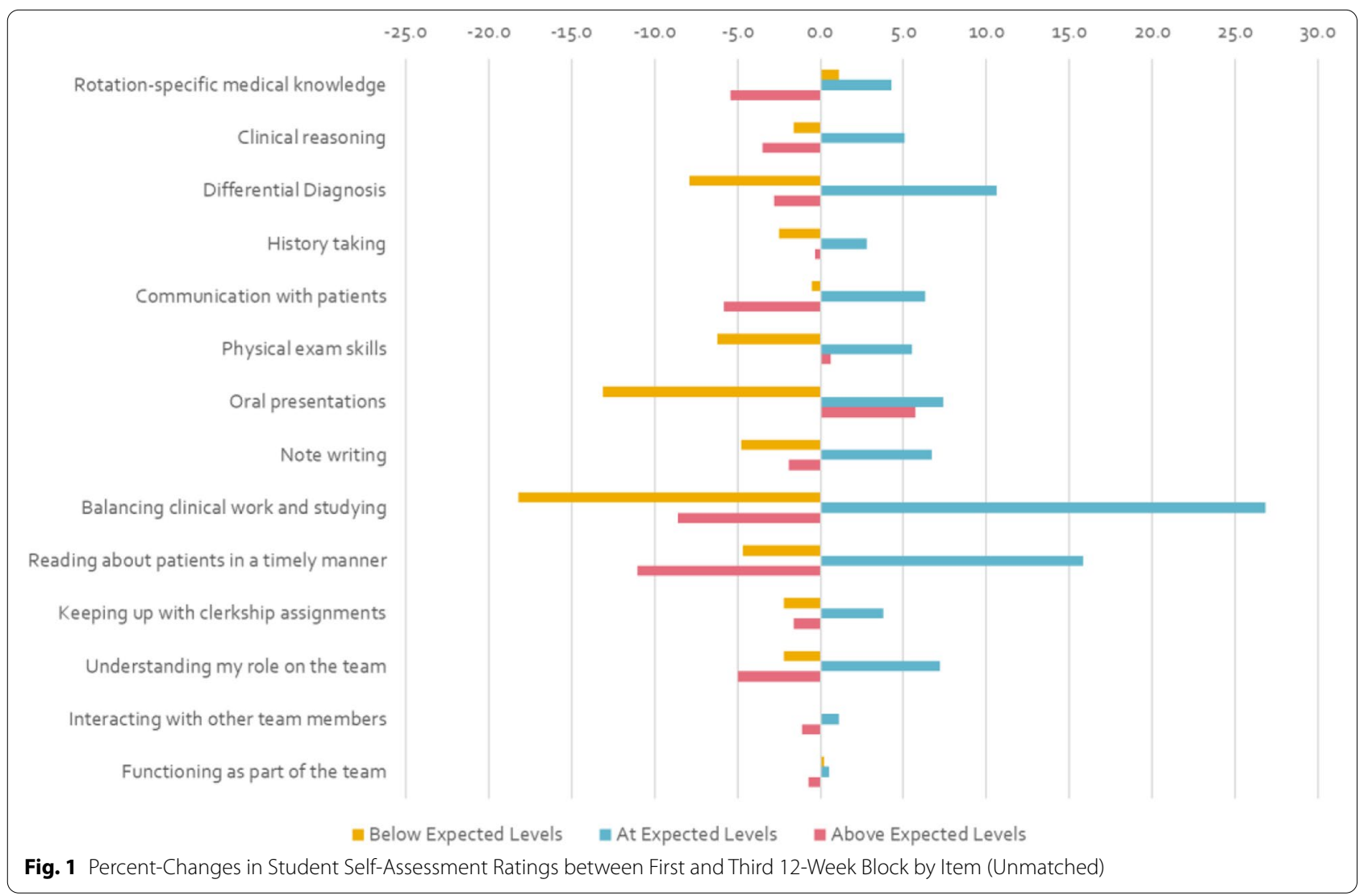




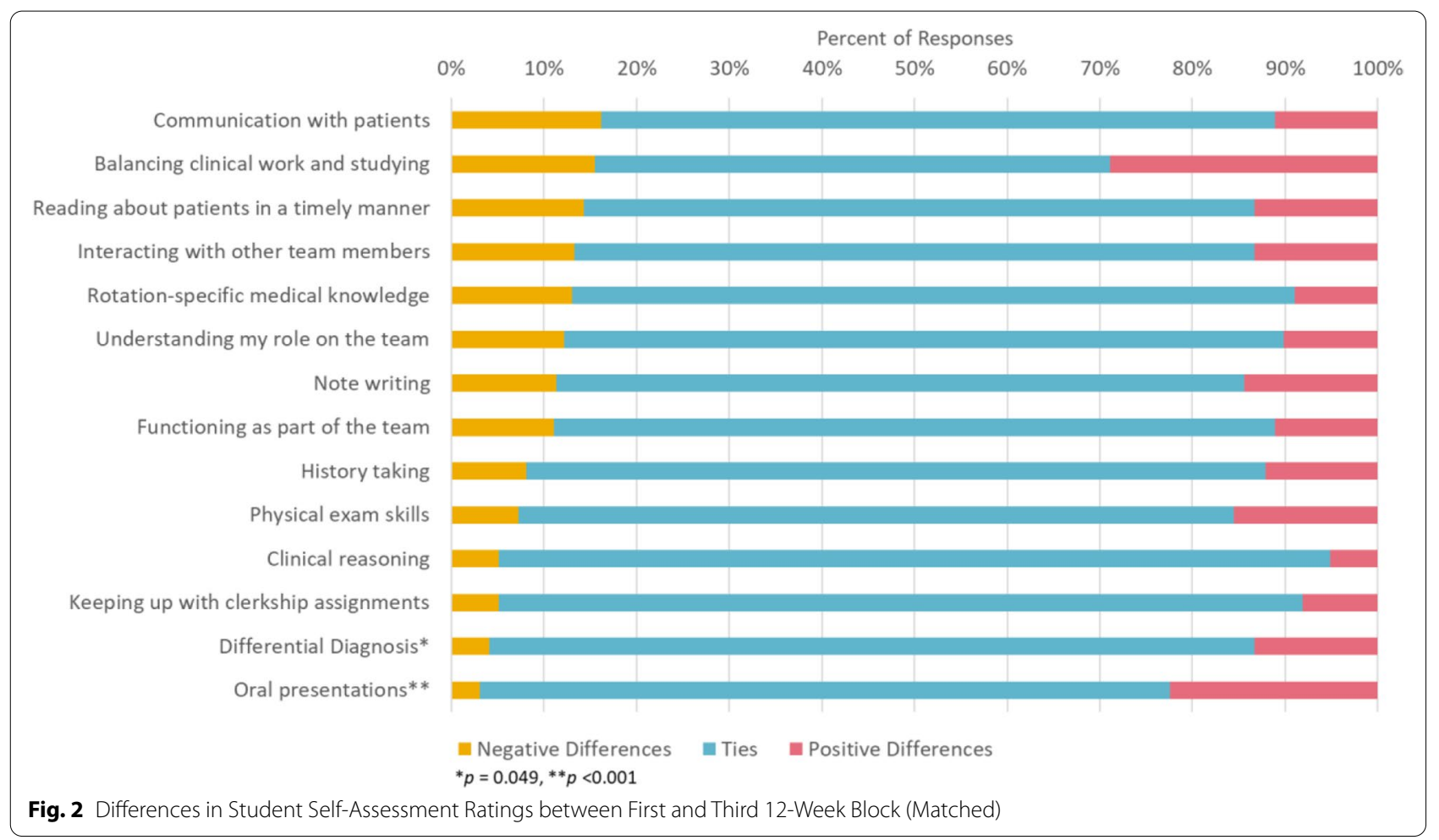

While statistically significant, it is important to note that the effect size estimates, for "Differential Diagnosis" in particular, are relatively small.

\section{Reflective comments}

Seven primary themes across the three open-ended items were identified in the initial sample (Block 1) and then applied to the second sample (Block 3) through directed content analysis (Table 2). Patient interaction was the most commonly identified area of strength/confidence in both samples with $37.2 \%$ and $43.9 \%$ of coded segments falling into this theme in Block 1 and Block 3, respectively. Statements such as, "I feel confident in history taking and providing an outlet for the patient to speak

Table 2 Proportion of Coded Segments Associated with Seven Primary Themes

\begin{tabular}{|c|c|c|c|c|}
\hline \multirow[t]{3}{*}{ Theme: Description } & \multicolumn{4}{|c|}{$\%$ of Coded Segments by Quarter } \\
\hline & \multicolumn{2}{|c|}{ Confidence } & \multicolumn{2}{|l|}{ Barriers } \\
\hline & $\begin{array}{l}\text { Block } 1 \\
(n=288)\end{array}$ & $\begin{array}{l}\text { Block } 3 \\
(n=205)\end{array}$ & $\begin{array}{l}\text { Block } 1 \\
(n=178)\end{array}$ & $\begin{array}{l}\text { Block } 3 \\
(n=114)\end{array}$ \\
\hline $\begin{array}{l}\text { Patient interaction: Refers to interpersonal communication skills and interviewing skills required with patient } \\
\text { care such as taking a pertinent history and building rapport. }\end{array}$ & 37.2 & 43.9 & 11.8 & 3.5 \\
\hline $\begin{array}{l}\text { Documentation/Reporting: Refers to ability to document and communicate clinical findings through writ- } \\
\text { ten (notes) and oral (presentations) formats. }\end{array}$ & 16.7 & 17.6 & 15.2 & 6.1 \\
\hline $\begin{array}{l}\text { Team/Structure/Workflow: Refers to ability to work within the healthcare team (point of confidence) or } \\
\text { trouble with personalities, expectations, or systemic issues as barriers. }\end{array}$ & 17.0 & 11.7 & 18.5 & 17.5 \\
\hline $\begin{array}{l}\text { Knowledge and Organization: Refers to medical knowledge broadly as well as rotation-specific knowledge. } \\
\text { Also includes study skills and worklife balance associated with studying. }\end{array}$ & 13.2 & 7.8 & 23.6 & 28.9 \\
\hline Physical exam: Refers to physical exam skills that are required during routine clinical encounters. & 5.6 & 9.8 & 11.2 & 10.5 \\
\hline $\begin{array}{l}\text { Clinical reasoning/information synthesis: Refers to ability to interpret clinical information and synthesize } \\
\text { it into a differential diagnosis and management plan. }\end{array}$ & 5.6 & 6.3 & 0.0 & 8.8 \\
\hline $\begin{array}{l}\text { Inexperience or Lack of Practice: Refers to expression of lack of confidence in certain skills due to limited } \\
\text { experience and/or a need to continue practicing. }\end{array}$ & 0.0 & 0.0 & 8.4 & 17.5 \\
\hline
\end{tabular}


because I tend to use open-ended questions and convey empathy quite easily" (Student 33, Block 1), were a common expression of this theme both in Block 1 and Block 3 . The theme was the most prevalent one in every rotation, but it appeared the most in the OB/GYN and Pediatrics rotation comments.

Knowledge and Organization was the theme most frequently cited as a barrier at both time points, but more so in Block 3 (23.6\% versus $28.9 \%$ ). Many of the comments in this theme were related to rotation-specific knowledge or the sheer volume of information there was to learn. One such comment was, "Time management - I feel like there is an incredible breadth of information I need to learn in $O B / G Y N$ that it is difficult for me to know how to learn it all while also being in a clinical setting. I also have responsibilities outside of clinical rotations that I am trying to juggle" (Student 75, Block 1).

Additional representative quotes from each theme for points of strengths and barriers are listed in Table 3.

\section{Discussion}

This is the first study examining changes in students' selfassessment longitudinally across multiple rotations over the course of their core clinical rotations. While the selfassessment component of our instrument was primarily aimed at guiding the narrative feedback and keeping it learner-centered, our review of the students' responses revealed interesting trends over time. Students demonstrated a significant positive shift in their perceived competence in core clinical skills such as developing differential diagnoses and delivering oral presentations. These shifts in ratings were partially supported by a significant decline from $17.6 \%$ to just $6.1 \%$ of students highlighting Documentation/Reporting skills as a barrier in their reflective comments. These improvements are not surprising given that practicing oral presentations and developing differential diagnoses are essential components of the core clinical rotations [21]. One study found that clinical faculty rated the expected baseline skill for oral presentations and differential diagnosis for students starting their rotations as lower than both their preclinical faculty colleagues and students themselves, which suggests an acknowledgment that these clinical skills are meant to be developed over the core year [22].

On the other hand, there was a significant negative shift in the students' perceived competence in their provider-patient communication skills. In fact, $16.2 \%$ of students rated themselves lower on these skills at Block 3 compared to Block 1 , nearly all from "Above expected level" to "At expected level". One potential explanation for this drop, is that students may have started by overrating their competence in this domain then moderated their perceived skills over time as they gained more experience. Such behavior would somewhat be expected given that communication skill training is highly emphasized during the preclinical phase of the curriculum, but relies heavily on scripted clinical encounters with simulated patients. In this setting, it is not surprising that students may highly rate their skills at the beginning of the clinical phase, only to be later challenged by actual clinical encounters. This explanation is also supported by previous studies that concluded students had a tendency to overestimate their skills in certain areas when self-assessing [3]. Another possible explanation may be that the observed change in ratings represents a true decline in communication skills as a result of negative role-modeling, time constraints, and competing interests once students start spending more time in actual clinical settings [23].

While it may not be possible to fully explain or rationalize the shifts is students' self-ratings over time, it is important to keep in mind that these ratings still reflect the students' perceptions of their performance and needs at different time points. As a matter of fact, we acknowledge that these individual perceptions may be anchored in a myriad measurable and unmeasurable factors including-but not limited to- self-defined performance targets, self-comparison to peers, and prior feedback received from patients or preceptors. Focus-group to identify from the students the range of inputs which caused changes in scores over time could have enhanced our understanding of the observed trends, and may be performed at a later stage as we continue to evaluate ways to modify the curriculum to meet student needs. Such analyses were not conducted for the purpose of this study as the focus here is on identifying student perceptions rather than explaining them.

We actually chose not to provide students with instructions on what defines "expected level" on the assessment instrument in order to collect a more accurate individual "needs assessment", in an effort to introduce student perceptions into the assessment of student performance, and to have it guide a learner-centered feedback process.

Medical training relies heavily on educator assessment as the primary mode to guide curriculum design and determine student success and achievement of clinical competency, with less value attached to learner selfassessment. In fact, the correlation between learner self-assessment and educator assessment of clinical skills is quite variable, with some studies showing some degree of correlation [24-27] and others showing very weak or no correlation [28-30]. While it is tempting to use these data to dismiss student self-assessment and perceptions as inaccurate, it is important to note that self-efficacy has been shown to be at least as important as the presence of knowledge and skill to student academic motivation 


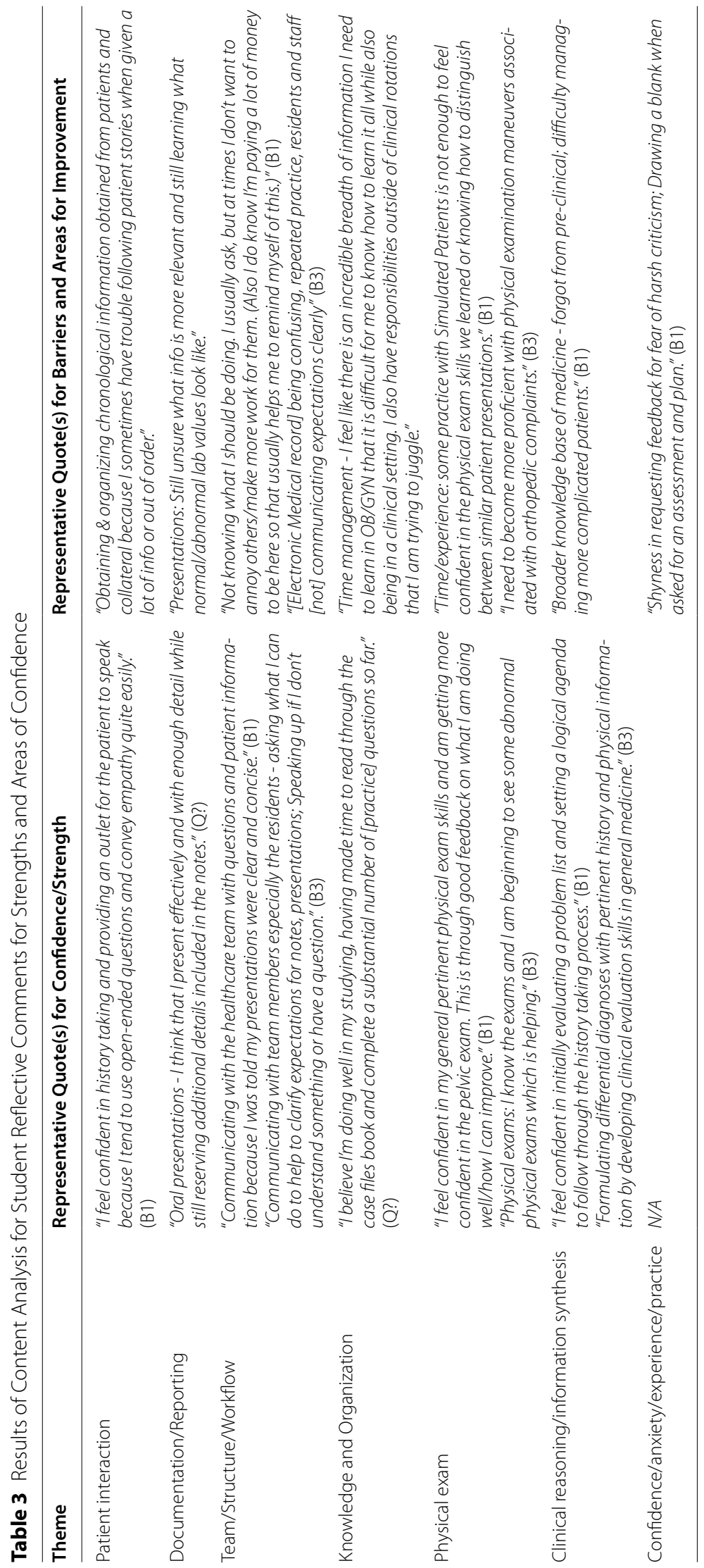


$[14,31,32]$. Consequently, educators would do well to tailor clinical curricula to meet the learners' perceived needs while still fostering acquisition of competency. For example, the findings from our study that we discuss in the previous paragraphs may be used to re-design clinical or even pre-clinical curricula in ways that place increased emphasis on presentation skills in the earlier phases and on communication skills in later phases.

Care should be exerted when generalizing these findings however, since our study was limited by its observational nature, by the fact that it took place at a single institution and by the rather limited sample size. Additionally, we used self-assessment ratings as a proxy for actual ability. Finally, we had no control over the order in which students took their rotations over the study period, so we cannot expect all students to have had the same experiences between the two measurement points. We worked to mitigate these limitations by using a repeated-measures design that compares students' Block 1 rating to their own Block 3 rating, by employing multiple data sources to triangulate our findings, and by sampling across the whole student cohort rather than focusing on a single specialty's rotation. Furthermore, all core clinical rotations follow a similar structure and they all offer comparable student involvement in care, educational activities, and grading criteria; therefore, the core progression in training should be equivalent across our sample despite having different rotations during Block 2.

\section{Conclusions}

In summary, student self-perceived needs and challenges during clinical rotations evolve over time; and the findings from this study may be used to inform the design of clinical curricula. While individual clinical rotations aim to introduce students to knowledge and practices specific to certain clinical disciplines (such as surgery, pediatrics etc.), it may be possible to create and reinforce a more unified clinical skills curriculum across different rotations. For example, one could envision a parallel curriculum that strongly emphasizes clinical reasoning and note writing early in the clinical phase, regardless of what rotations the students are on, and that revisits communication skills at a later stage in order to address the real-life challenges that students would have experienced by then.

\section{Supplementary Information}

The online version contains supplementary material available at https://doi. org/10.1186/s12909-021-02985-1.

Additional file 1.
Acknowledgements

The authors thank Dana Hartman for her assistance.

\section{Authors' contributions}

PB participated in the project design, performed the data analyses, and was a major contributor in writing the manuscript. $\mathrm{RH}$ was a major contributor to data extraction, and participated in data analyses and the writing of the manuscript. ASH was a major contributor to the study conception and design and in writing the manuscript. All authors read and approved the final manuscript.

\section{Funding}

No funds, grants, or other support was received.

\section{Availability of data and materials}

The datasets generated during and/or analyzed during the current study are not publicly available student confidentiality.

\section{Declarations}

Ethics approval and consent to participate

Ethical approval was waived by the local Ethics Committee of the University of lowa Carver College of Medicine in view of the retrospective nature of the study and all the procedures being performed were part of the routine care.

Consent for publication

Not applicable.

Competing interests

The authors have no relevant financial or non-financial interests to disclose.

\section{Author details}

${ }^{1}$ Department of Internal Medicine, University of lowa Carver College of Medicine, 1216H MERF, 375 Newton Rd, IA 52242-2600 lowa City, USA. ${ }^{2}$ Department of Pathology, University of lowa, IA, lowa, USA.

Received: 22 April 2021 Accepted: 15 October 2021

Published online: 29 October 2021

\section{References}

1. Pangaro L, McGaghie WC. Handbook on medical student evaluation and assessment. 1st ed. Syracuse: Gegensatz Press; 2015.

2. Cruess SR. Professionalism and medicine's social contract with society. Clin Orthop Relat Res. 2006;449:170-6. doi:https://doi.org/10.1097/01.blo. 0000229275.66570 .97$.

3. Isenberg GA, Roy V, Veloski J, Berg K, Yeo CJ. Evaluation of the validity of medical students' self-assessments of proficiency in clinical simulations. J Surg Res. 2015;193:554-9. doi:https://doi.org/10.1016/j.jss.2014.09.036.

4. Davis DA, Mazmanian PE, Fordis M, Harrison RV, Thorpe KE, Perrier L. Accuracy of physician self-assessment compared with observed measures of competence. JAMA. 2006;296:1094-102. doi:https://doi.org/10.1001/ jama.296.9.1094.

5. Black P, Wiliam D. Assessment and classroom learning. Assess Educ 1998;5:7-74. doi:https://doi.org/10.1080/0969595980050102.

6. Black P, Wiliam D. Developing the theory of formative assessment. Educ Asse Eval Acc. 2009;21:5. doi:https://doi.org/10.1007/s11092-008-9068-5.

7. McMillan J, Hearn J. Student self-assessment: the key to stronger student motivation and higher achievement. Educ Horiz. 2008;87:40-9. http:// www.jstor.org/stable/42923742.

8. Bercher DA. Self-monitoring tools and student academic success: when perception matches reality. J Coll Sci Teach. 2012;41:26-32.

9. Ibabe I, Jauregizar J. Online self-assessment with feedback and metacognitive knowledge. High Educ. 2010;59:243-58. doi:https://doi.org/10. 1007/s10734-009-9245-6.

10. Siegesmund A. Increasing Student Metacognition and Learning through Classroom-Based Learning Communities and Self-Assessment. J Microbiol Biol Educ. 2016: 204-14. doi: https://doi.org/10.1128/jmbe.v17i2.954. 
11. Bandura A. Social foundations of thought and action: a social cognitive theory. Englewood Cliffs: Prentice Hall; 1986.

12. Schunk DH, Pintrich PR, Meece JL. Motivation in education: theory, research, and applications. 3rd ed. Upper Saddle River: Pearson Education; 2008.

13. Schunk DH. Self-efficacy and academic motivation. Educ Psychol. 1991:26:207-31. doi:https://doi.org/10.1080/00461520.1991.9653133.

14. Pintrich PR, De Groot EV. Motivational and self-regulated learning component of classroom academic performance. J Educ Psychol. 1990;82:33-40. doi:https://doi.org/10.1037/0022-0663.82.1.33.

15. Klassen RM, Klassen JRL. Self-efficacy beliefs of medical students: a critical review. Perspect Med Educ. 2018;7:76-82. doi:https://doi.org/10.1007/ s40037-018-0411-3.

16. Hochberg M, Berman R, Ogilvie J, Yingling S, Lee S, Pusic M, et al. Midclerkship feedback in the surgical clerkship: the "Professionalism, Reporting, Interpreting, Managing, Educating, and Procedural Skills" application utilizing learner self-assessment. Am J Surg. 2017;213:212-6. doi:https:// doi.org/10.1016/j.amjsurg.2016.08.001.

17. Creswell JW, Plano Clark VL. Designing and Conducting Mixed Methods Research. 3rd ed. Thousand Oaks: Sage; 2018.

18. Rosenthal R, Rubin DB. r equivalent: A simple effect size indicator. Psychol Methods. 2003:8:492-6. doi:https://doi.org/10.1037/1082-989X.8.4.492.

19. Cohen J. Statistical Power Analysis for the Behavioral Sciences. New York: Routledge Academic; 1988.

20. Hsieh H-F, Shannon SE. Three approaches to qualitative content analysis Qual Health Res. 2005;15:1277-88. doi:https://doi.org/10.1177/10497 32305276687.

21. Williams DE, Surakanti S. Developing oral case presentation skills: peer and self-evaluations as instructional tools. Ochsner J. 2016 Spring;16:65-9. PMID: 27046408; PMCID: PMC4795506.

22. Wenrich $M$, Jackson MB, Scherpbier AJ, Wolfhagen IH, Ramsey PG, Goldstein EA. Ready or not? Expectations of faculty and medical students for clinical skills preparation for clerkships. Med Educ Online 2010;15. doi:https://doi.org/10.3402/meo.v15i0.5295.

23. Malhotra A, Gregory I, Darvill E, Goble E, Pryce-Roberts A, Lundberg K, et al. Mind the gap: Learners' perspectives on what they learn in communication compared to how they and others behave in the real world. Patient Educ Couns. 2009;76:385-90. doi:https://doi.org/10.1016/j.pec 2009.07.024.

24. Talwalkar JS, Murtha TD, Prozora S, Fortin AH 6th, Morrison LJ, Ellman MS. Assessing advanced communication skills via objective structured clinical examination: a comparison of faculty versus self, peer, and standardized patient assessors. Teach Learn Med. 2020;32:294-307. doi:https://doi.org/ 10.1080/10401334.2019.1704763.

25. Stahl CC, Jung SA, Rosser AA, Kraut AS, Schnapp BH, Westergaard M, Hamedani AG, Minter RM, Greenberg JA. Entrustable professional activities in general surgery: trends in resident self-assessment. J Surg Educ. 2020;77:1562-7. doi:https://doi.org/10.1016/j.jsurg.2020.05.005.

26. Chow I, Nguyen VT, Losee JE, Goldstein JA, Spiess AM, Solari MG, Rubin JP, Gusenoff JA. Milestones in plastic surgery: attending assessment versus resident assessment. Plast Reconstr Surg. 2019;143:425e-432e. doi:https://doi.org/10.1097/PRS.0000000000005214.

27. Elhadi M, Ahmed H, Khaled A, Almahmoudi WK, Atllah SS, Elhadi A, Esahli $H$. Informed self-assessment versus preceptor evaluation: a comparative study of pediatric procedural skills acquisition of fifth year medical students. BMC Med Educ. 2020;20:318. doi:https://doi.org/10.1186/ s12909-020-02221-2.

28. Tanoue N, Korovin LN, Carton M, Galvani CA, Ghaderi I. Faculty feedback versus residents' self-assessment of operative performance: Different but complementary. Am J Surg. 2018;215:288-92. doi:https://doi.org/10. 1016/j.amjsurg.2017.11.016

29. Alameddine MB, Claflin J, Scally CP, Noble DM, Reames BN, Englesbe MJ, Wong SL. Resident surgeons underrate their laparoscopic skills and comfort level when compared with the rating by attending surgeons. J Surg Educ. 2015;72:1240-6. doi:https://doi.org/10.1016/j.jsurg.2015.07.002.

30. Habib SR, Sherfudhin H. Students' self-assessment: a learning tool and its comparison with the faculty assessments. J Contemp Dent Pract. 2015;16:48-53. doi:https://doi.org/10.5005/jp-journals-10024-1634.

31. Artino AR. Academic self-efficacy: from educational theory to instructional practice. Perspect Med Educ. 2012;1:76-85. https://doi.org/10. 1007/s40037-012-0012-5.

32. Multon KD, Brown SD, Lent RW. Relation of self-efficacy beliefs to academic outcomes: a meta-analytic investigation. J Counsel Psychol. 1991;38:30-8. https://doi.org/10.1037/0022-0167.38.1.30.

\section{Publisher's Note}

Springer Nature remains neutral with regard to jurisdictional claims in published maps and institutional affiliations.
Ready to submit your research? Choose BMC and benefit from:

- fast, convenient online submission

- thorough peer review by experienced researchers in your field

- rapid publication on acceptance

- support for research data, including large and complex data types

- gold Open Access which fosters wider collaboration and increased citations

- maximum visibility for your research: over $100 \mathrm{M}$ website views per year

At BMC, research is always in progress.

Learn more biomedcentral.com/submissions 